\title{
High sequence homology between protein tyrosine acid phosphatase from boar seminal vesicles and human prostatic acid phosphatase ${ }^{\star}$
}

\author{
Paweł Wysocki ${ }^{1 凶}$, Grażyna Płucienniczak ${ }^{2}$ and Jerzy Strzeżek ${ }^{1}$ \\ ${ }^{1}$ Department of Animal Biochemistry and Biotechnology, University of Warmia and Mazury in Olsztyn, \\ Poland; ${ }^{2}$ Institute of Biotechnology and Antibiotics, Warszawa, Poland
}

Received: 26 May, 2009; revised: 08 September, 2009; accepted: 15 September, 2009

available on-line: 17 September, 2009

\begin{abstract}
Boar seminal vesicle protein tyrosine acid phosphatase (PTAP) and human prostatic acid phosphatase (PAP) show high affinity for protein phosphotyrosine residues. The physico-chemical and kinetic properties of the boar and human enzymes are different. The main objective of this study was to establish the nucleotide sequence of cDNA encoding boar PTAP and compare it with that of human PAP cDNA. Also, the amino-acid sequence of boar PTAP was compared with the sequence of human PAP. PTAP was isolated from boar seminal vesicle fluid and sequenced. cDNA to boar seminal vesicle RNA was synthesized, amplified by PCR, cloned in $E$. coli and sequenced. The obtained N-terminal amino-acid sequence of boar PTAP showed $92 \%$ identity with the N-terminal amino-acid sequence of human PAP. The determined sequence of a 354 bp nucleotide fragment (GenBank accession number: GQ184596) showed 90\% identity with the corresponding sequence of human PAP. On the basis of this sequence a 118 amino acid fragment of boar PTAP was predicted. This fragment showed $89 \%$ identity with the corresponding fragment of human PAP and had a similar hydropathy profile. The compared sequences differ in terms of their isoelectric points and amino-acid composition. This may explain the differences in substrate specificity and inhibitor resistance of boar PTAP and human PAP.
\end{abstract}

Keywords: boar, phosphorylation, prostatic acid phosphatase, protein tyrosine phosphatase, seminal plasma

\section{INTRODUCTION}

Phosphorylation and dephosphorylation of sperm and seminal plasma proteins are regulated by the opposing activities of kinases and phosphatases (Visconti \& Kopf, 1998; Urner \& Sakkas, 2003). Evidence has shown that changes in protein tyrosine phosphorylation are associated with sperm motility activation, hyperactivation, capacitation and fertilization (Naz, 1996; Kalab et al., 1998; Si \& Okuno, 1999). It is well known that anatomically developed seminal vesicle glands of the boar reproductive tract play a dominant secretory role. Boar seminal plasma is characterized by a high acid phosphatase activity (Mann \& Lutwak-Mann, 1981). Electrophoretic studies of boar seminal plasma showed the pres- ence of four isoenzymes of acid phosphatase originating in the epididymal, prostatic and vesicular fluids (Wysocki \& Strzeżek, 2000). Boar protein tyrosine acid phosphatase (PTAP) isolated from the seminal vesicle fluid is a thermostable glycoprotein with a molecular mass of about $42 \mathrm{kDa}$. The enzyme showed high activity when phosphotyrosine and tyrosine-phosphorylated polypeptides were used as substrates (Wysocki \& Strzeżek, 2003). The purified boar epididymal form of acid phosphatase is a thermostable $50 \mathrm{kDa}$ protein, with a $\mathrm{pI}$ value of 7.1. Isolated epididymal form of boar acid phosphatase exhibited lower affinity to phosphotyrosine compared with the vesicular form. The N-terminal amino-acid sequences of the boar epididymal acid phosphatase showed high homology with mouse, rat and human

${ }^{\square}$ Corresponding author: Paweł Wysocki, Department of Animal Biochemistry and Biotechnology, University of Warmia and Mazury in Olsztyn, Oczapowskiego 5, 10-719 Olsztyn, Poland; tel.: (48) 89523 3509, fax: (48) 89 524 0138, e-mail: pawel.wysocki@uwm.edu.pl

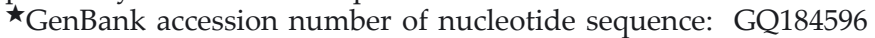

Abbreviations: AcP, acid phosphatase; PAP, prostatic acid phosphatase; PTAP, protein tyrosine acid phosphatase; PVDF, polyvinylidene fluoride. 
prostatic acid phosphatases (Wysocki \& Strzeżek, 2006). However, both enzymes isolated from the boar reproductive tract are resistant to $\mathrm{L}(+)$-tartaric acid, a selective inhibitor of human PAP.

Human prostatic acid phosphatase has been of significant medical interest ever since tests screening for serum PAP levels were successfully used to diagnose prostate cancer. The enzyme produced by the human prostate gland is found in the seminal plasma at high concentrations of nearly $1 \mathrm{mg} / \mathrm{ml}$ (Ostrowski \& Kuciel, 1994). The results of many examinations have shown that human PAP, as a phosphotyrosine phosphatase, plays an important role in signal transduction pathways and cancer development (Lin et al., 1998; Veeramani et al., 2005).

The main objective of this study was to establish the nucleotide sequence of cDNA encoding PTAP isolated from boar seminal vesicle fluid. The secondary objective was to analyze the nucleotide and amino-acid sequences of boar PTAP and compare them with those of human PAP.

\section{MATERIALS AND METHODS}

Isolation of protein tyrosine acid phosphatase. Protein tyrosine acid phosphatase (PTAP) was isolated from boar seminal vesicle fluid as described by Wysocki and Strzeżek (2003). Isolated protein, after chemical deglycosylation (Solar \& Bahl, 1987) and electrotransfer on PVDF membrane (Millipore), was sequenced at the BioCentrum (Kraków, Poland). Phenylthiohydantoin derivatives of amino acids were identified using a Procise 491 (Applied Biosystems, Foster City, CA, USA) automatic sequence analysis system and a standard protocol of the manufacturer.

RNA isolation and cDNA synthesis. Total RNA was isolated from boar seminal vesicles as described by Chomczynski and Sacchi (1987). cDNA to boar seminal vesicle RNA was synthesized using the cDNA Synthesis system (Roche) and a standard protocol of the manufacturer.

PCR and cloning. In the first stage of this study degenerated primers were used, the sequences of which were designed on the basis of obtained Nterminal amino-acid sequence of boar PTAP. Primers designed on the basis of conserved nucleotide sequences occurring in genes coding for other phos- phatases of mammalian semen were also used. The main sequence used in this study was a $110 \mathrm{bp}$ fragment from exon 4 of the porcine acid phosphatase gene (van Poucke et al., 2001).

Additionally, a modified gene amplification procedure was applied, which included ligation of synthetic oligonucleotides to the ends of cDNA and then amplification using primers complementary to the added oligonucleotide and conserved sequences from exon 4 of the porcine acid phosphatase gene.

The PCR reaction was performed in a buffer containing $20 \mathrm{mM}$ Tris $/ \mathrm{HCl}, 50 \mathrm{mM} \mathrm{KCl}, 2.5 \mathrm{mM}$ $\mathrm{MgCl}_{2}$ (pH 8.9), $0.02 \mathrm{mM}$ of each dNTP, $50 \mathrm{pmol}$ of each primer, $2 \mathrm{U}$ of $\mathrm{Taq}$ polymerase (Stratagene) and $100 \mathrm{ng}$ of cDNA as a template in the final volume of $50 \mu \mathrm{l}$. The reaction was performed for 25 cycles using an Eppendorf 5330 thermocycler. Each cycle consisted of $2 \mathrm{~min}$ at $95^{\circ} \mathrm{C}, 30 \mathrm{~s}$ at $94^{\circ} \mathrm{C}$ and $30 \mathrm{~s}$ at $55^{\circ} \mathrm{C}$. The amplified cDNA fragment was isolated by polyacrylamide gel electrophoresis as described previously (Dybczynski \& Plucienniczak, 1988), phosphorylated with phage T4 polynucleotide kinase and treated with the Klenow fragment of Escherichia coli DNA polymerase I in the presence of $1 \mathrm{mM}$ dNTP to remove 3 '-overhangs introduced by Taq DNA polymerase (Clark, 1988). The obtained product was treated with phenol and chloroform/isoamyl alcohol mixture $(24: 1, \mathrm{v} / \mathrm{v})$, ethanol precipitated, digested with HindIII and ligated to HindIII-digested pBS SK+ plasmid (Stratagene).

Recombinant plasmids were transferred into E. coli strain DH5 $\alpha$ (Sambrook et al., 1989). Bacterial cells were cultured on LB agar plates supplemented with $100 \mu \mathrm{g} / \mathrm{ml}$ ampicillin. After overnight incubation at $37^{\circ} \mathrm{C}$ single bacterial colony was transferred to $100 \mathrm{ml}$ of LB broth containing $100 \mu \mathrm{g} / \mathrm{ml}$ ampicillin and incubated overnight at $37^{\circ} \mathrm{C}$ with shaking. The isolation of recombinant plasmids was performed by the alkaline lysis method (Birnboim \& Doly, 1979). Plasmids from several independent clones were sequenced using an ABI 373 sequencer and sequencing kit, as recommended by the manufacturer (Amersham). Database searches were performed using the National Institutes of Health ENTREZ and BLAST software (Altshul et al., 1997).

Amino-acid sequence analysis. Analysis of the deduced amino-acid sequence (isoelectric point, hydrophobicity) was performed with the CLCBio Protein Workbench computer software (CLC Bio).

Table 1. Comparison of N-terminal amino-acid sequences of boar seminal vesicle PTAP with corresponding human and rat acid phosphatase sequences.

Amino acids which are different between these sequences are shadowed.

\begin{tabular}{lll}
\hline Acid phosphatase & Sequence & Reference \\
\hline Boar PTAP-ase & KELRFVTLVFRHG & this paper \\
Human and rat PAP & KELKFVTLVFRHG & Vihko et al. (1988); Roiko et al. (1990) \\
Human lysosomal AcP & RSLRFVTLLYRHG & Pohlmann et al. (1988) \\
Human testis AcP & GPLVFVALVFRHG & Yousef et al. (2001) \\
\hline
\end{tabular}




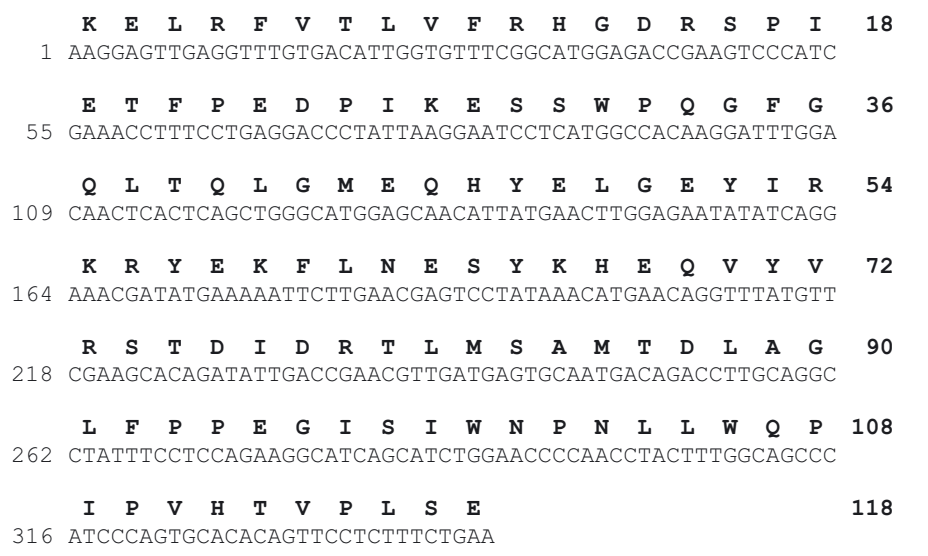

$\begin{array}{llllllllllllllllllll}\text { E } & \text { T } & \text { F } & \text { P } & \text { E } & \text { D } & \text { P } & \text { I } & \text { K } & \text { E } & \text { S } & \text { S } & \text { W } & \text { P } & \text { Q } & \text { G } & \text { F } & \text { G } & 36\end{array}$

\author{
18 \\ 108
} 118

The method of Kyte and Doolittle (1982) was used for protein hydrophobicity determination.

\section{RESULTS}

The sequencing of isolated boar PTAP resulted in the determination of the N-terminal aminoacid sequence, which showed $92 \%$ homology with sequences of acid phosphatases isolated from human and rat prostates. However, in the case of the enzyme isolated from the boar seminal plasma, arginine (R) was found at position 4 instead of lysine $(\mathrm{K})$, which occurs in the human and rat enzymes. Furthermore, boar PTAP showed only slightly low54 72
Figure 1. Sequences of 354 nucleotides of cDNA encoding boar seminal vesicle protein tyrosine acid phosphatase (PTAP) and of corresponding 118 amino acids. er homology with human lysosomal and testicular acid phosphatases fragments (Table 1).

Using primers designed on the basis of the Nterminal amino-acid sequence it was not possible to obtain PCR products homologous to the sequences of other seminal acid phosphatases. This was probably due to the composition of the N-terminal amino-acid sequence. The designed primers were highly degenerated and insufficiently complementary to the cDNA sequence encoding boar PTAP.

Using the modified amplification procedure we obtained a $354 \mathrm{bp}$ fragment. Its nucleotide sequence and the amino-acid sequence are shown in Fig. 1. This fragment showed $90 \%$ identity with the sequence of human PAP (Fig. 2A). On the basis of

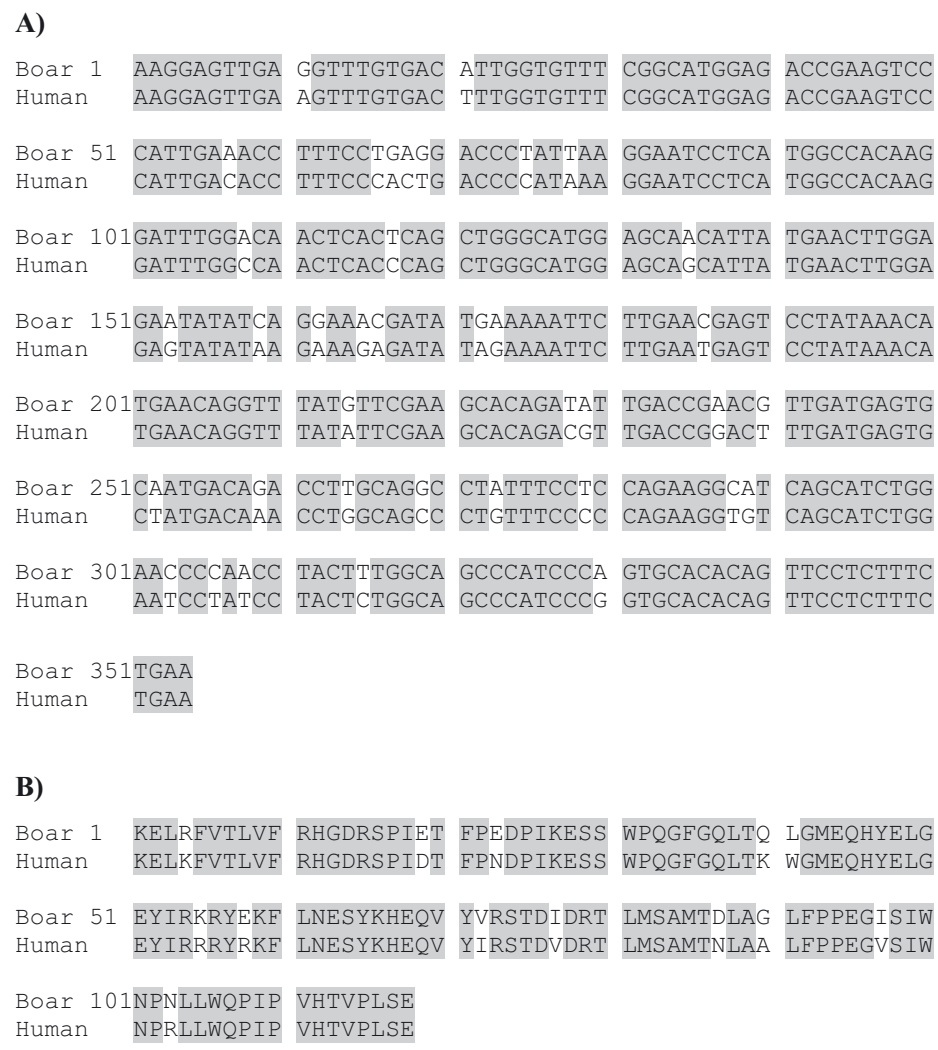

Figure 2. Homology between boar seminal vesicle PTAP and human PAP at the nucleotide (A) and amino acid (B) levels. Identical regions are shadowed. 

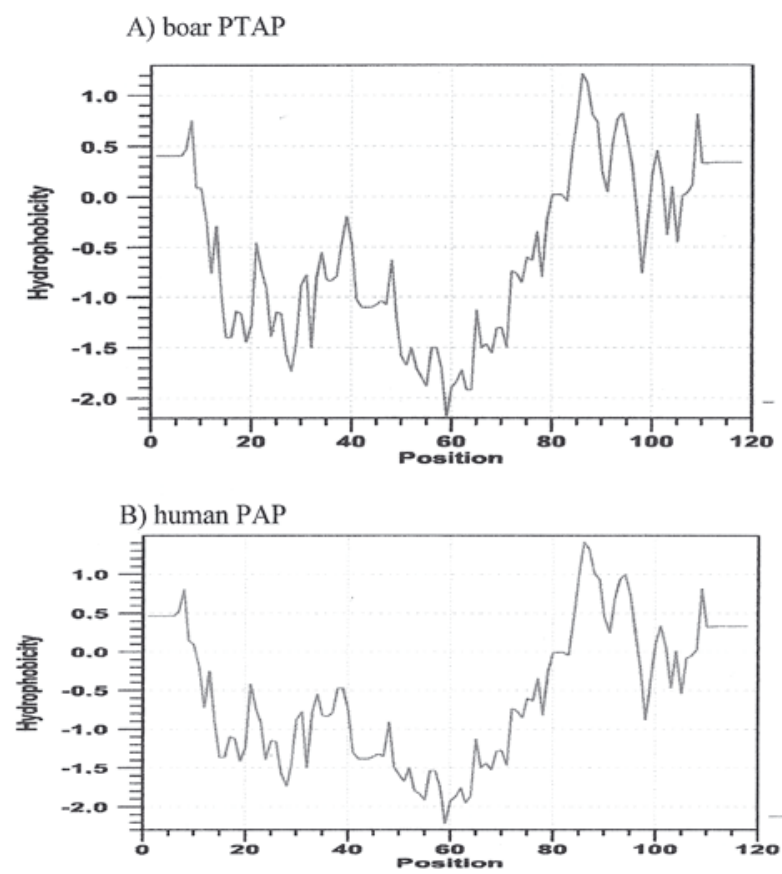

Figure 3. Hydrophobicity plot of boar PTAP and human PAP fragments.

this nucleotide sequence a 118 amino acid fragment of boar PTAP was predicted. This fragment showed $89 \%$ homology with the corresponding amino-acid sequence of human PAP (Fig. 2B).

The differences in the amino-acid sequences did not result in changes in the hydropathy profiles of the analyzed polypeptides. In both polypeptides hydrophilic sequences were located in the 10-30 aa and 50-70 aa segments (Fig. 3).

Despite numerous attempts it was not possible to determine the complete nucleotide sequence of the cDNA encoding boar PTAP. The obtained fragments did not exhibit homology with sequences of acid phosphatases that have been recently identified.

\section{DISCUSSION}

Human prostatic acid phosphatase hydrolyses a wide range of alkyl and aryl orthophosphate monoesters, including phosphotyrosine and nucleotides (Apostol et al., 1985). In addition, human PAP has also been found to dephosphorylate phosphotyrosine residues in peptides and proteins. A molecular form of acid phosphatase with a high affinity for phosphotyrosine residues has also been isolated and characterized from boar seminal vesicle fluid (Wysocki \& Strzeżek, 2003). The human PAP cDNA encodes a 354-residue protein with a calculated molecular mass of $41126 \mathrm{Da}$. In the 5' end, the
cDNA codes for a signal peptide of 32 amino acids (Vihko et al., 1988). In the case of boar PTAP cDNA isolated from seminal vesicles, the sequence encoding the signal peptide was not detected. The human PAP active site, which contains an essential H12 residue, is located in a large open cleft between two domains, thus enabling the enzyme to accept a wide variety of substrates. Residues R11, H12 and R15 are part of a sequence motif RHGXRXP, characteristic of acid phosphatases. In boar PTAP and human PAP the RHGDRSP motifs are present. These residues are part of a cluster of conserved amino acids in the center of the active site, consisting of residues of R11, H12, R15, R79, H257 and D258. Three putative asparagine-linked glycosylation sites were detected in the human PAP sequence: NES (residues 62-64), NFT (residues 188-190) and NET (residues 301-303) (Vihko et al., 1988). A potential N-glycosylation site (NES; residues 62-64) was also found in the analyzed domain of boar PTAP.

The human PAP monomer has been shown to contain three disulphide bonds between cysteines 129/340, 183/281 and 315/319 (van Etten et al., 1991). Within the analyzed fragment of boar PTAP no cysteine was found. They are probably located in the further part of the molecule, similarly to the human PAP.

In diluted solutions, several active oligomeric PAP species exist, in a concentration-dependent dissociation/association equilibrium. At concentrations lower than $100 \mathrm{nM}$ of human PAP the monomer prevails, whereas at higher concentrations active oligomers are formed (Luchter-Wasylewska et al., 2003).

Our earlier studies indicated that boar PTAP exists in the active form as a monomer with a molecular mass of approx. $42 \mathrm{kDa}$ and $\mathrm{pI}=7.1$ (Wysocki \& Strzeżek, 2003).

Within the analyzed amino-acid sequence of boar PTAP there is one more aspartic acid residue (D) compared with human PAP. On the other hand, a lower number of lysyl residues (K) (4 residues) was detected in comparison to the analogous fragment of human PAP (6 residues), and an identical number of arginines (R) (9 residues). These differences in the proportions of acidic and alkaline amino-acid residues result in different $\mathrm{pI}$ values calculated for the compared sequences (not shown). In the case of the boar PTAP fragment the $\mathrm{pI}$ value was found to be approx. 6.5, whereas it was approx. 8.5 for the corresponding human PAP fragment.

The analyzed fragments of human PAP and boar PTAP exhibit considerable homology, although the differences in the amino-acid composition result in divergent values of the isoelectric point. Moreover, boar PTAP is not sensitive to the inhibitory action of tartaric acid (Wysocki \& Strzeżek, 2003). 
Binding of $\mathrm{L}-(+)$-tartrate ions to the active site of human PAP is due to the electrostatic interaction between the enzyme and the anionic ligand and extensive hydrogen bonding between the hydroxyl group of the tartrate ion and the enzyme molecule. Upon the inhibitor binding human PAP does not undergo a significant structural change. Minor changes occur in the active site arginine (R 11, 15, 79) and histidine (H 12, 257) residues (Bem \& Ostrowski, 2001). It seems that the lower isoelectric point of boar PTAP (at least of the fragment analyzed) does not provide sufficiently strong electrostatic interactions between the enzyme molecule and $\mathrm{L}-(+)-$ tartate ions within the active centre. This may possibly result in a lack of sensitivity of the enzyme isolated from the boar seminal vesicle fluid to the inhibitory action of tartrate.

Despite their similar amino-acid sequences, human PAP and boar PTAP exhibit different structural and kinetic characteristics (Wysocki \& Strzeżek, 2003). This is probably the effect of the different anatomical structure of the reproductive system and species-specific reproduction processes. It needs to be underlined that in the case of both species the dominant secretory accessory glands (human - prostate, boar - vesicle glands) are the sources of acid phosphatases which exhibit affinity for phosphotyrosine residues of proteins. In the case of human, prostatic acid phosphatase is secreted at high concentrations (approx. $1 \mathrm{mg} / \mathrm{ml}$ ), which promotes the formation of the enzyme oligomeric structure. In contrast, in the boar, due to the large volume of the ejaculate and high activity of acid phosphatases in the epididymal fluid, the enzyme is secreted by the seminal vesicles at lower concentrations, which contributes to the formation of the monomer. Recent studies have indicated that PTAP plays a significant role in the regulation of tyrosine phosphorylation of proteins of boar spermatozoa, especially during cryopreservation (Wysocki et al., 2009).

\section{Acknowledgements}

The authors would like to thank Dr. L. Fraser for kindly reviewing the manuscript.

This work was supported by grants from the State Committee for Scientific Research (PBZ-KBN084/P06/2002) and University of Warmia and Mazury in Olsztyn (0103.0803).

\section{REFERENCES}

Altshul SF, Madden TL, Schaffer AA, Zhang J, Miller W, Lipman DJ (1997) Gapped BLAST and PSI-BLAST: a new generation of protein database search programs. Nucleic Acids Res 25: 3389-3402.
Apostol I, Kuciel R, Wasylewska E, Ostrowski WS (1985) Phosphotyrosine as a substrate of acid and alkaline phosphatase. Acta Biochim Polon 32: 187-197.

Bem S, Ostrowski WS (2001) Effect of tartaric acid on conformation and stability of human prostatic phosphatase: an infrared spectroscopic and calorimetric study. Acta Biochim Polon 48: 755-762.

Birnboim HC, Doly J (1979) A rapid alkaline extraction procedure for screening recombinant plasmid DNA. Nucleic Acids Res 7: 1513-1523.

Chomczyński P, Sacchi N (1987) Single-step method of RNA isolation by acid guanidinium thiocyanate-phenol-chloroform extraction. Anal Biochem 162: 156-159.

Clark JM (1988) Novel non-templated nucleotide addition reactions catalyzed by prokaryotic and eukaryotic DNA polymerases. Nucleic Acids Res 16: 9677-9686.

Dybczyński I, Płucienniczak A (1988) A protocol for DNA fragment extraction from polyacrylamide gels. Biotechniques 6: 924-926.

Kalab P, Peknicova J, Geussova G, Moos J (1998) Regulation of protein tyrosine phosphorylation in boar sperm through a cAMP-dependent pathway. Mol Reprod Dev 51: 304-314.

Kyte J, Doolittle R (1982) A simple method for displaying the hydropathic character of a protein. J Mol Biol 157: 105-132.

Lin MF, Meng TC, Rao PS, Chang C, Schntal AH, Lin FF (1998) Expression of human prostatic acid phosphatase correlates with androgen-stimulated cell proliferation in prostate cancer cell lines. J Biol Chem 273: 5939-5947.

Luchter-Wasylewska E, Wasylewski M, Röhm K-H (2003) Concentration-dependent dissociation/association of human prostatic acid phosphatase. J Protein Chem 22: 243-247.

Mann T, Lutwak-Mann C (1981) Male reproductive function and semen. Themes and trends in physiology, biochemistry and investigative andrology. Springer Verlag, Berlin.

Naz RK (1996) Involvement of protein tyrosine phosphorylation of human sperm in capacitation/acrosome reaction and zona pellucida binding. Front Biosci 1: 206213.

Ostrowski WS, Kuciel R (1994) Human prostatic acid phosphatase: selected properties and practical applications. Clin Chim Acta 226: 121-129.

Pohlmann R, Krentler C, Schmidt B, Schroder W, Lorkowski G, Culley J, Mersmann G, Geier C, Waheed A, Gottschalk S, Grzeschik K-H, Hasilik A, Figura K (1988) Human lysosomal acid phosphatase: cloning, expression and chromosomal assignment. EMBO J 7: 2343-2350.

Roiko K, Janne OA, Vihko P (1990) Primary structure of rat secretory acid phosphatase and comparison to other acid phosphatases. Gene 89: 223-229.

Sambrook J, Fritsh EF, Maniatis T (1989) Molecular Cloning. A Laboratory Manual. Cold Spring Harbor Laboratory Press.

Si Y, Okuno M (1999) Role of tyrosine phosphorylation of flagellar proteins in hamster sperm hyperactivation. Biol Reprod 61: 240-246.

Solar HT, Bahl OP (1987) Chemical method for the deglycosylation of proteins using trifluoromethanesulfonic acid (TFMS). Arch Biochem Biophys 259: 52-57.

Urner F, Sakkas D (2003) Protein phosphorylation in mammalian spermatozoa. Reproduction 125: 17-26.

van Etten RL, Davidson R, Stevis PE, MacArthur H, Moore DL (1991) Covalent structure, disulfide bonding and identification of reactive surface and active site resi- 
dues of human prostatic acid phosphatase. J Biol Chem 266: 2313-2319.

van Poucke M, Yerle M, Tuggle C, Piumi F, Genet C, van Zeveren A, Peelman LJ (2001) Integration of porcine chromosome 13 maps. Cytogenet Cell Genet 93: 297-303.

Veeramani S, Yan T-C, Chen S-J, Lin F-F, Petersen JE, Shaheduzzaman S, Srivastava S, MacDonald RG, Lin M-F (2005) Cellular prostatic acid phosphatase: a protein tyrosine phosphatase involved in androgen-independent proliferation of prostate cancer. Endocr Relat Cancer 12: 805-822.

Vihko P, Virkkunen P, Henttu P, Roiko K, Solin T, Huhtala ML (1988) Molecular cloning and sequence analysis of cDNA encoding human prostatic acid phosphatase. FEBS Lett 236: 275-281.

Visconti PE, Kopf GS (1998) Regulation of protein phosphorylation during sperm capacitation. Biol Reprod 59: $1-6$.
Wysocki P, Strzeżek J (2000) Molecular forms of acid phosphatase of boar seminal plasma. Anim Sci Pap Rep 18: 99-106.

Wysocki P, Strzeżek J (2003) Purification and characterization of a protein tyrosine acid phosphatase from boar seminal vesicle glands. Theriogenology 59: 1011-1025.

Wysocki P, Strzeżek J (2006) Isolation and biochemical characteristics of a molecular form of epididymal acid phosphatase of boar seminal plasma. Theriogenology 66: 2152-2159.

Wysocki P, Koncicka K, Strzeżek J (2009) Is the phosphorylation status of tyrosine proteins a marker for cryocapacitation of boar spermatozoa? Bull Vet Inst Pulawy 53: 229-232.

Yousef GM, Diamandis M, Jung K, Diamandis EP (2001) Molecular cloning of a novel human acid phosphatase gene (ACPT) that is highly expressed in the testis. Genomics 74: 385-395. 